\title{
Features of autonomous and parallel operation of an asynchronous generator with a network of endless power in the current stage of EPS development
}

\author{
Yunus Bobojonov ${ }^{1}$, Tolqin Alibekova ${ }^{1}$, Asror N Sultonov ${ }^{2}$, Polat $_{\text {Quwatbaev }}{ }^{1}$, Atabek Ismandiyarov ${ }^{1}$ \\ ${ }^{1}$ Karakalpak State University, Nukus, Uzbekistan \\ ${ }^{2}$ Tashkent State Technical University
}

\begin{abstract}
The article describes the use of asynchronous machines in generator mode to provide power to threephase consumers, as well as the features of autonomous and parallel operation of an asynchronous generator with an infinite power network. The use of static sources of reactive power allows widespread introduction of an asynchronous generator in the electric power system as a reliable source of active power.

Key words: self-excitation of an asynchronous generator, static source of reactive power, absolute slip value, dynamic stability.
\end{abstract}

\section{Introduction}

In recent years, considerable interest has been caused by the use of asynchronous machines (brushless) in generator mode to provide power to three-phase consumers.

As you know, the use of asynchronous generators (AG) is limited by the fact that they are active power generators and consumers (from outside) of reactive power. Consequently, AGs are capable of operating only in systems in which there are sources of reactive power. These can be either a system in which the source of reactive power is a synchronous machine, which also performs the function of a synchronous compensator, or a static source of reactive power [1-6].

AG are used as peak load generators at small hydroelectric power plants operating without maintenance personnel, since they can be operated without frequency and voltage control systems. It is also known to use AG as generators of wind power plants.

\section{The mathematical statement of the problem}

AGs are distinguished by high reliability and ease of maintenance in operation, they are easily switched on in parallel operation even with relatively large mismatches of angular velocities. The shape of the voltage curve of the AG is closer to sinusoidal than that of synchronous generators (SG) when operating on the same load, it is more resistant to short circuits and overloads [10-12].

The principle of operation of the AG is as follows: When the rotational speed rises above the idle speed (due to the drive unit), the asynchronous machine switches to the generator mode, sequentially covering the mechanical and additional no-load losses, electrical (idle) and main magnetic losses in the stator for due to the mechanical power of the drive motor. The emf and the rotor current change signs. The electromagnetic torque becomes braking. It changes its phase by $180^{\circ}$ and the active stator current, determined by the magnitude of the active load of the generator [7-9].

The energy diagram allows you to judge the nature of the distribution of power consumed by the motor from the network. It can be obtained using the diagram below (Fig. 1):

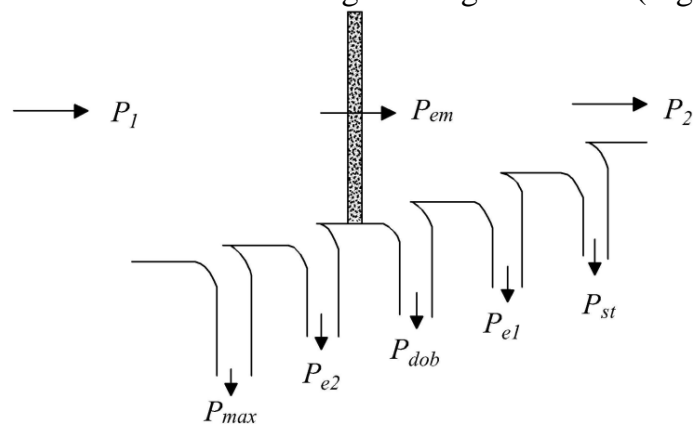

Fig.1. Energy diagram of power conversion of an asynchronous generator

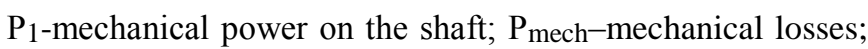
$\mathrm{P}_{\mathrm{e} 2-}$-losses in the rotor winding; $\mathrm{P}_{\mathrm{em}}$ - electromagnetic power; $\mathrm{P}_{\text {dob-additional losses; }} \mathrm{P}_{\mathrm{e} 1 \text {-losses }}$ in the stator winding; $\mathrm{P}_{\mathrm{st}}{ }^{-}$ losses in steel; $\mathrm{P}_{2}$-generator net power.

It should be noted that the reactive component of the stator current, determined by the values of the magnetizing current and the current compensating for the power of the dissipation fields of the stator and rotor windings in the 
generator mode, as in the motor mode, will have the same phase (inductive in relation to the mains voltage).

During autonomous operation of the $\mathrm{AG}$, the reactive component of the AG current and the load is compensated by the capacitive current in the capacitor bank. The equivalent circuit of the AG phase, which forms an autonomous network with a load $\mathrm{Z}_{\mathrm{L}}$, is shown in Fig. 2.

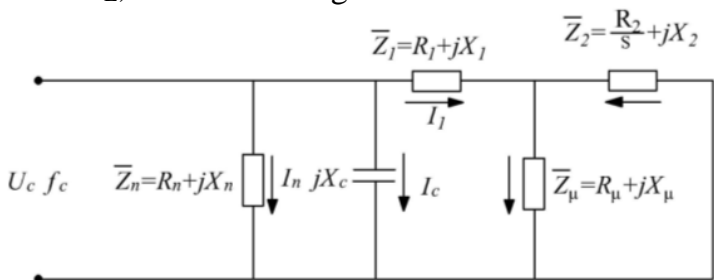

Fig. 2. Equivalent circuit of a self-excited AG

The process of self-excitation of the AG is explained in Fig. 3. The residual EMF with $A G$, due to the magnetization of the rotor Eos, when it disappears, is restored by short-term switching on of the stator winding to the network. For selfexcitation of the AG to the required EMF, the capacitance of the capacitor is required.

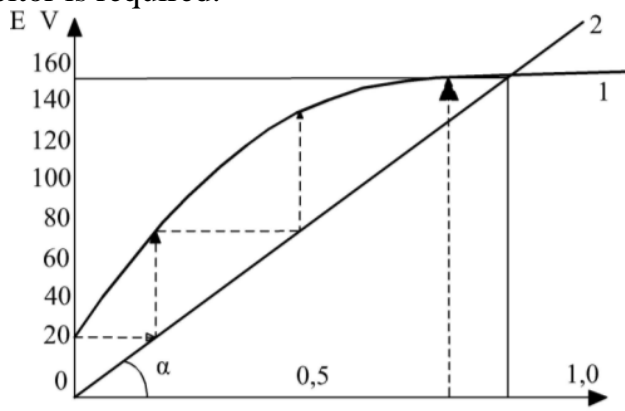

Fig. 3. AG self-excitation process

1 - characteristic of idling of the AG; 2 - dependence of the voltage across the capacitor on the capacitor current

The required battery capacity $\mathrm{C}$ must exceed a certain critical value $\mathrm{C}_{0}$, which depends on the parameters of an autonomous asynchronous generator: only in this case, the generator self-excites and a three-phase symmetric voltage system is installed on the stator windings. The voltage value ultimately depends on the characteristics of the machine and the capacitance of the capacitors [13-18].

The required reactive power $\mathrm{Q}$ of capacitors for exciting induction generators is determined by:

$$
\mathrm{Q}=0.314 \cdot \mathrm{U} 2 \cdot \mathrm{C} \cdot 10^{-6} \text {, }
$$

where: $\mathrm{C}$-the capacitance of the capacitors, $\mu \mathrm{F}$.

With AG load (increase in the absolute value of slip s), the voltage decreases due to an internal voltage drop and a decrease in emf $E_{1}$ as a result of a decrease in the network frequency.

The most effective voltage stabilization is with additional regulating capacitors. In this case, the capacitors not only compensate for the reactive current of the $\mathrm{AG}$, but also change the operating point of the magnetic characteristic of the generator, compensating for the internal voltage drop.

Voltage stabilization with increasing $\mathrm{s}$ is possible by increasing $\mathrm{P}_{1}$ and, consequently, $\mathrm{f}_{1}$.

When the AG operates on a network of comparable power, the constancy of $U_{c}, f_{c}$ is ensured by appropriate over excitation of synchronous machines operating on the network and compensating for the reactive component of the $A G$ current and the network load.

The operation of an asynchronous machine in a generator mode on a high-power network $\left(\mathrm{U}_{\mathrm{c}}=\right.$ const, $\left.\mathrm{f}_{\mathrm{c}}=\mathrm{const}\right)$ is described by the same equations, an equivalent circuit, as in the motor mode, with the exception of the slip sign $(s<0)$. The voltage and frequency of the generator are the same as those in the network. The useful power of the generator depends only on the rotor speed, which is set automatically, respectively, the power of the drive.

The study of the problem of generation and distribution of reactive power in modern electric power systems (EPS) and possible, from a technical and economic point of view, ways to cover the required reactive power of the AG show the following:

In the incoming part of the balance of reactive power in the EPS, one should take into account: the charging power of the transmission line, the available reactive power of the SG, the power of various sources of reactive power and an increase in the voltage class of the transmission line and the distance.

Despite, the wide possibilities for regulating reactive power both in terms of output and consumption, synchronous compensators have a number of disadvantages, which, in particular, include; the presence of rotating parts, inertia, an increase in the short-circuit power, relatively high operating costs, etc. Meanwhile, the operating modes of modern EPS require almost instantaneous voltage regulation in the system.

Static sources of reactive power (SSRP) are devoid of these disadvantages, Their speed is $2-4$ periods, they allow you to regulate the voltage in phases, solve a number of problems of a regime nature and, according to experts, are 1.5-2 times cheaper than synchronous compensators of the same capacity [19-23].

The noted trends in the development of power systems show the expediency of the layout of power plants with a mixed composition of $\mathrm{SG}$ and $\mathrm{AG}$, which improves the operating conditions of the SG, since the reactive power available by them will be used. As studies show, in this case, the level of static and dynamic stability of the SG, its reliability increases, and the technical and economic indicators of the station and the system as a whole improve.

It may also be possible to reduce the number and capacity of reactors installed at the starting end of the transmission, which requires justification on a case-by-case basis.

The widespread introduction of SSRP will make it possible to create long-distance AC power lines with a station at the starting end, entirely consisting of AGs with their own and evenly distributed along the line. The indisputable advantages of the proposed power transmission are: no problem of dynamic stability in its traditional sense, practically unlimited length, the ability to take off power at any point in the line.

\section{Conclusions}

Thus, the modes of modern power systems, the observed trend and new technical means for the generation and distribution of reactive power solve the problem of covering the reactive power of the $A G$ and open up prospects for the creation of long-range and ultra-long-range $\mathrm{AC}$ power 
transmissions. Experiments have shown that the introduction of powerful AGs into modern EPS is a reliable and technically feasible way to improve their static and dynamic properties.

\section{References}

1. S. Vaez-Zadeh and E. Jalali, "Combined vector control and direct torque control method for high performance induction motor drives," Energy conversion and management, vol. 48, pp. 3095-3101, 2007.

2. Casadei D, Profumo F, Serra G, Tani A (2002) FOC and DTC: two viable schemes for induction motors torque control. IEEE Trans Power Electron 17(5):779-787

3. Diab AAZ (2017) Implementation of a novel full-order observer for speed sensorless vector control of induction motor drives. Elect Eng 99(3):907-921.

4. Diab AAZ, Kotin DA, Pankratov VV (2013) Speed control of sensorless induction motor drive based on model predictive control. In: Micro/Nanotechnologies and Electron Devices (EDM), 2013 14th International Conference of Young Specialists on, IEEE conference, vol., no., pp 269274

5. I.Rakhmonov, A.Berdishev, N.Niyozov, A.Muratov and U.Khaliknazarov. Development of a scheme for generating the predicted value of specific electricity consumption // CONMECHYDRO - 2020. IOP Conf. Series: Materials Science and Engineering. $883 \quad$ (2020) 012103. doi:10.1088/1757-899X/883/1/012103

6. F.A.Hoshimov, I.I.Bakhadirov, M.S.Kurbanbayeva, N.A.Aytbayev. Development of specific standards of energy consumption by types of produced products of the spinning product // RSES 2020. E3S Web of Conferences. 216 (2020) 01169. https://doi.org/10.1051/e3sconf/202021601169

7. F.A.Hoshimov, I.I.Bakhadirov, A.A.Alimov, M.T.Erejepov. Forecasting the electric consumption of objects using artificial neural networks // E3S Web of Conferences. 216 (2020) 01170.

8. I.U.Rakhmonov, F.A.Hoshimov. Development of an algorithm for evaluating the dominant factors that have the greatest impact on the energy intensity of products // ENERGY-21. E3S Web of Conferences. 209 (2020) 07018. https://doi.org/10.1051/e3sconf/202020907018

9. Usmanov E.G. Stability in a parallel resonant circuit with active load // RSES 2020. E3S Web of Conferences. 216 (2020) 01160. https://doi.org/10.1051/e3sconf/202021601160 10. Usmanov E.G., Khusanov B.M. Phase relations in resonant circuits with a wide falling section on the amplitude characteristic // RSES 2020. E3S Web of Conferences. 216 (2020) 01161. https://doi.org/10.1051/e3sconf/202021601161 11. I.U.Rakhmonov, K.M.Reymov and S.H.Dustova. Improvements in industrial energy rationing methods // MIP: Engineering-2020. E3S Web of Conferences. 862 (2020) 062070. doi:10.1088/1757-899X/862/6/062070

12. I.U.Rakhmonov, K.M.Reymov. Statistical models of renewable energy intermittency // RSES 2020. E3S Web of $\begin{array}{llll}\text { Conferences. } & 216 & \text { (2020) } & 01167 .\end{array}$ https://doi.org/10.1051/e3sconf/202021601167

13. I.U.Rakhmonov, N.N.Kurbonov. Analysis of automated software for monitoring energy consumption and efficiency of industrial enterprises // E3S Web of Conferences. 216 (2020) 01178. https://doi.org/10.1051/e3sconf/202021601178 14. F.A.Hoshimov, I.U.Rakhmonov, N.N.Niyozov. Technology to reduce energy costs in the electric steel melting shop // ENERGY-21. E3S Web of Conferences. 209 (2020) 07017. https://doi.org/10.1051/e3sconf/202020907017 15. I.Bakhadirov, N.Markaev, G.Aslanova, R.Tanatarov, S.Makhmuthonov. Differentiated tariffs of electricity for the improvement of steelmaking Uzbekistan // CONMECHYDRO - 2020. IOP Conf. Series: Materials Science and Engineering. $883 \quad$ (2020) 012121. doi:10.1088/1757-899X/883/1/012121

16. A.D.Taslimov. Selection of a complex of parameters of distribution electric networks with respect to technical limitations // ENERGY-21. E3S Web of Conferences. 209 (2020) 07013. https://doi.org/10.1051/e3sconf/202020907013 17. Olimjon Toirov, Allabergan Bekishev, Sardor Urakov and Utkir Mirkhonov E3S Web of Conferences 216, 01116 (2020), https://doi.org/10.1051/e3sconf/202021601116

18. Olimjon Toirov,Kamoliddin Alimkhodjaev, Nurali Pirmatov and Aziza Kholbutaeva E3S Web of Conferences 216, $01119 \quad$ (2020), https://doi.org/10.1051/e3sconf/202021601119

19. K.M.Reymov, G.Turmanova, S.Makhmuthonov, B.Uzakov. Mathematical models and algorithms of optimal load management of electrical consumers // E3S Web of $\begin{array}{llll}\text { Conf. } & 216 & \text { (2020) }\end{array}$ https://doi.org/10.1051/e3sconf/202021601166

20. A.N.Rasulov, M.R.Ruzinazarov, N.Toirova, T.Sh.Alibekova. Graphical-analytical method for constructing load characteristics // RSES 2020. E3S Web of Conferences. $216 \quad 01171$. https://doi.org/10.1051/e3sconf/202021601171

21. Yu.Bobozhonov, B.Seytmuratov, B.Fayzullaev, A.Sultonov. Study of the influence of different designs of massive rotor of asynchronous generator on their maximum power // RSES 2020. E3S Web of Conferences. 216 (2020) 01177. https://doi.org/10.1051/e3sconf/202021601177

22. Rakhmonov I U, Reymov K M, Najimova A M, Uzakov B T and Seytmuratov BT 2019 Analysis and calculation of optimum parameters of electric arc furnace Journal of Physics: Conference Series 1399 doi:10.1088/17426596/1399/5/055048

23. Yu.M.Bobozhonov, K.M.Reymov, B.T.Seytmuratov, T.Kh.Khakimov. Research of the dependence of the resistance of asynchronous generators with massive rotors on their design // RSES 2020. E3S Web of Conferences. 216 (2020) 01168. https://doi.org/10.1051/e3sconf/202021601168 